\title{
Industry 4.0 Learning Factory: a canvas for specifications
}

\author{
François Marmier, ${ }^{\mathrm{a}, *}$ Ivana Rasovska ${ }^{\mathrm{a}}$, Lorène Dubreuil ${ }^{\mathrm{b}}$, Bertrand Rose $^{\mathrm{a}}$ \\ a'ICube (UMR-CNRS 7357), Université de Strasbourg, 67000 Strasbourg, France \\ ${ }^{b}$ IUT de Haguenau, Université de Strasbourg, 67500 Haguenau, France
}

\begin{abstract}
The digitalisation increase in industrial processes is perceived as an opportunity to grow up the competitiveness of companies. Data is more and more accessible, potentially allowing making better decisions at all levels of the company. Then, job profiles and their required skills are changing, becoming more and more focused on new technologies and information systems. The most effective way to acquire necessary skills is a "learning by doing" way in industrial projects and processes. At the crossroad of the academic and the industrial environment, a Learning Factory becomes the most appropriate pedagogical mean. It allows running combinations of theoretical and applied tools in the context of industry 4.0. On the other hand, a LF can also be used to design and to simulate production systems in order to optimize the transition to industry 4.0. The transition 4.0 addresses both technological and industrial needs. A LF 4.0 project must also meet extra pedagogical needs. The interactions between these needs are complex and make LF 4.0 projects special, especially for the specification refinement phase. In this paper we propose a model and a canvas to develop pertaining specifications for a LF 4.0. The originality of our work is to consider the analysis of the technological, industrial and pedagogical needs to formalize the specifications. Based on these proposals, the University of Strasbourg evolved its existing LF for the manufacturing industry for the 4.0. In this paper, we illustrate our proposal from this project.
\end{abstract}

(C) 2021 The Authors. This is an open access article.

Peer Review statement: Peer-review under responsibility of the scientific committee of the 11th Conference on Learning Factories 2021.

Keywords: Industry 4.0; Competency approach; Learning factory design; Project; Specification

\section{Introduction}

In the current context of globalization where companies must increase their competitiveness, digitization can appear as a solution. The many digital tools, associated with technological advances, bring the consumer and all production stakeholders closer together. The factory 4.0 is thus more adaptable to customer demand and this across the entire logistics chain. It is therefore necessary for staff to develop new skills such as process simulation, ergonomic analysis based on digital twin, in order to be able to use these new tools and implement new practices. However, it turns out that many employees lack training to enable companies to take full advantage of the potential of Industry 4.0. In addition, if only one of the links in a logistics chain does not have these skills, the entire chain loses efficiency.

Companies expressed the willingness to recruit young graduates who are quickly operational, but also to send their staff for training so that they quickly acquire well-targeted skills. To answer this request our university increases its offer of training in this field at technician or middle management levels.

The best way to learn is to practice. A Learning Factory (LF) allows reproducing concrete industrial issues on a small scale. For this reason, the IUT Haguenau of the University of Strasbourg decided to design a dedicated LF to 4.0, based on existing LF for the manufacturing industry. A LF 4.0 that addresses the whole problematics of the transition 4.0 should consider the technological changes and the industrial needs. That generates specific

\footnotetext{
* Corresponding author. Tel.: +33 388053400

E-mail address: marmier@unistra.fr
} 
pedagogical needs that also have to be considered in the frame of a LF 4.0 project. It becomes necessary to define a map of the needs that have to be satisfied. Such a map will allow the development of the specification for a LF 4.0.

The rest of this article is structured as follows: in the following section, we present a state of the art on training in LF and particularly within the context of Industry 4.0 as well as a feedback from our experience with existing LF. In section 3, we formulate a model of the needs to satisfy with a LF 4.0 and a canvas to define the specifications of a LF 4.0. Section 4 illustrates our proposals on the basis of the LF 4.0 project we developed. Finally, we conclude the paper with a discussion and our perspectives.

\section{State of the art on Learning Factories for Industry 4.0}

\subsection{Academic state of the art on LF projects}

The industry is changing with an increase of robotisation and the adaptation of the workstations to permit the co-working between robots and humans [1]. Job roles are redefined and request support from the academic system that has to follow the change. In such a context, the change process requires an alignment of the learning objectives on the challenges of the industry 4.0 [2]. It is not a question of only developing new training. Existing ones, such as the Lean management [3], activity management or other transversal activities [4] have to be first mastered and then enhanced in the 4.0 context. Therefore, we observe many projects of LF in the literature. We can distinguish two kinds of projects: (1) the development of brand new LF such as Leal et al. who initiated a LF for the Industry 4.0 dissemination in Brazil [5]; (2) the transformation (or upgrade) of existing LF following about a similar transformation than the Industry itself. Our work falls within this second framework of the context since we already had an LF for Lean training. Various questions arise such as which specificity of the 4.0 have to be integrated first, how to adapt the pedagogy... Several LFs already existed before the desire/requirement to integrate 4.0 into training. This is the case with the iwb's learning factory, described by Bauer et al. They developed a methodology in the form of problem-based learning approach. Challenges related to the field of 4.0 are given to participants who have to create new solutions by gaining knowledge autonomously. Focused on the training on decisionmaking, Oberc et al. developed a process presenting cognitive assistance in front of the increasing amount of data in the 4.0 context [6]. Abele et al. proposed a study on how to define a LF starting from specific goals [7]. The redesign of our LF therefore corresponds to the last phase of the LF lifecycle defined in: LF Remodeling/Recycling. In our knowledge, there is no dedicated work linking the different needs involved in a LF 4.0 project.

\subsection{Industrial state of the art}

The methodology of transformation towards the factory of the future for many companies involves the acquisition of a showroom based on new technologies. This purchase is often decided by the top management of the company without first having the vision and the assurance of having competent personnel who can make this showroom a real factory that works. However, the implications of digital transformation occur throughout the production chain: at the product design stage with digital simulation or augmented reality; at the time of production control and management with the Internet of Things or PLM; on manufacturing processes (additive or cobotic manufacturing); on predictive maintenance with artificial intelligence but also on work organisation. At the same time, it also opens a reflection on organisational processes and a redefinition of workstations. Several years ago, we started the cooperation with industrial partners to define future jobs and their natures (https://www.disrupt40.fr/) through different working groups and within 3 defined axes: skills and training needs in the connected company and the mapping of existing courses (initial and continuing) in Alsace (Grand Est Region), new technologies and softwares for the value chain in the industry of the future and the digitalization of Lean projects.

\subsection{Trainings on LF at the University of Strasbourg}

Currently, our Learning Factory is very close to a real factory with poles that can be interconnected physically and numerically. However, they require an evolution in terms of training tools. The LF focuses on the place of man and organisation in the vast field of industrial production. The production hall has already ten reconfigurable assembly stations, MES software developed in-house, ERP such as Divalto, ePrélude or Dynamics Navision, flow simulation software such as Plant simulation and Witness, a metrology laboratory equipped with Mitutoyo machines, six exoskeletons of different types, a Hanel dynamic store as well as line-side supermarkets. The current system of our LF allows us to provide practical training in all aspects of industrial engineering and Lean 
manufacturing. We assure the practical training within diplomas Bachelor and Master's degree in both initial and continuing forms.

Our project of LF 4.0 should lead to develop trainings that support the transformation 4.0 in companies, at the different levels of professions. This should also follow the evolution of the industry' objectives by making our answers evolve through training, modules, and the evolution of technologies.

\subsection{Survey on the satisfaction of past students}

To assess the relevance of our training on the LF, from the students' point of view, we conducted a survey of 45 students who received training between 2015 and 2019. This training took place partly on the first version of our LF in the fields of Lean and Lean 4.0. We received 19 responses, i.e. a rate of $42 \%$. This allows an understanding of the perception of the students. All the students of the selected course have a professional experience of several years beforehand. $22 \%$ of them were sent to this training at the initiative of their company. This makes them more apt for constructive criticism. In addition, $31 \%$ of them have an LF in their company and can therefore compare. If for $94 \%$ of them, practicing on LF is essential in the areas of Lean and 4.0, not all of them reject traditional courses. $63 \%$ thought that the LF made the course interesting and for the remaining $37 \%$ it was even essential. However, $21 \%$ believe that some lessons should be maintained in the form of traditional lessons. Back to the company, $100 \%$ of students recognize that their level of competence in these areas has increased significantly. $80 \%$ have had an evolution in their career following the training (change of job, function or company) and $100 \%$ recommend their training. Taking a step back from what they have learned, various comments are made: desire for a global project on LF; wish for more course content on digitization, change management and management.

\section{A canvas to design the specification of a Learning Factory 4.0}

The main tendency that drives the transition 4.0 is a bottom-up approach. The evolution of the industrial practices lead to the decisions of new competences development and most of the time to the acquisition of new technology. On the other hand, some industries use a top-down approach when top management decides purchasing new technologies to increase their visibility in a competitive market. These acquisitions lead to found industrial uses for these technologies and most of the time to develop new skills. Both scenarios must take into account the different needs in terms of new technologies and/or the specifications of the different functions in the company. This demand generates an educational need and universities are trying to respond to by means of LF adapted to 4.0. Such LF have therefore for specification to be able to address various kinds of training on technologies 4.0 and on organisational, flow and quality management in the context of industry 4.0. A project of LF starts, as most of projects, with a deepening phase of the need. This phase permits clarifying the specifications necessary to identify different equipment to acquire as well as pedagogical modules and training scenarios to develop.

\subsection{Model for the interrelations of the needs}

The analysis of needs leads us to propose the model presented in Fig. 1. This model links the technological needs often imposed by the market and with industrial needs of different functions in the enterprise. Considering the fact that companies may have a technological need, once satisfied, this one may lead to a pedagogical need to help them to develop the adequate professional skills. Entry points on the model are therefore possible from the 3 different needs presented in the model following the source of the initial need. Therefore, a circular representation of needs fits well.

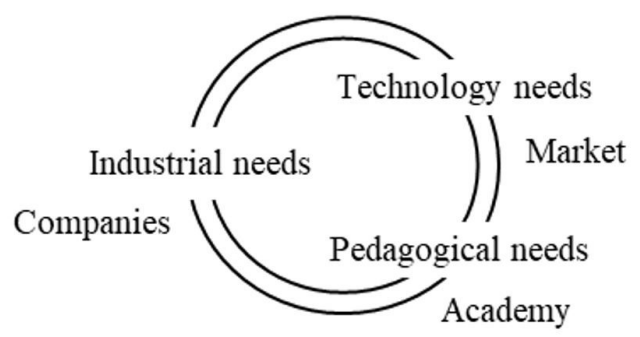

Fig. 1. Needs' circle.

In the case companies are in front of an Industrial need to satisfy the changes of the work due to the 4.0 evolution, this one could in one way directly lead to a pedagogical need for training on organisational, flow and 
quality management. In another way it could lead to a technological need and after its satisfaction, by the acquisition of new technology, leads to a pedagogical need for training on how to use this technology in the most efficient way. In the case of classical training at the university, the LF will help to satisfy the various trainings helping students to address industrial and technological challenges of the 4.0 transition.

\subsection{Toward specifications for the development of a $L F 4.0$}

In the context of Industry 4.0, the pedagogical needs that universities have to satisfy are at the crossroads of the Technological needs and the Industrial needs of the companies. The technological needs emerges from nine technologies impacting the companies and defined in (www.i-scoop.eu/industry-4-0). This concerns advanced robotics, additive manufacturing, augmented reality, simulation, horizontal/vertical integration of data based on data transfer standards, industrial internet, cloud, cybersecurity and big data and analytics but this could evolve in the future. The first characteristic of LF is then the possible evolution of the system in terms of technology. The factory is scalable to be able to illustrate, measure and practice different scenarios of a transition.

The industrial needs can be classified thanks to the diagnostic tool proposed in [8]. A global model was developed bringing together four areas of transformation 4.0: process/product design, production/logistics/maintenance, strategic organisation and finally eco-responsible area. Each area is detailed in several axes (industrial functions) such as for example production/logistics/maintenance is divided into control/command, quality/traceability, assembly or flow management and characterised by three different evolution steps. This model allows companies, for all the areas of the transformation 4.0 to know the level of performance to reach and the strategies to be adopted.

The Pedagogical needs are linked to both technology and industrial needs in terms of equipment and competencies to acquire. The proposed approach here consists in developing pedagogical answers at the intersection of the technological and the industrial needs. By browsing the intersections of the nine technologies previously described and the axis of the diagnostic tool proposed in [8], it is possible to design a map of the requirements of pedagogical answers. To develop a LF 4.0 that accompanies all the specificity of the transition 4.0, specifications should therefore be proposed to cover the whole map.

\section{Illustration of the new specifications for the LF 4.0 of the University of Strasbourg}

The specifications defined through the needs' circle and the interrelation crossboard allow to evolve the already existing and functional LF of the University of Strasbourg.

\subsection{Technological and informatics components}
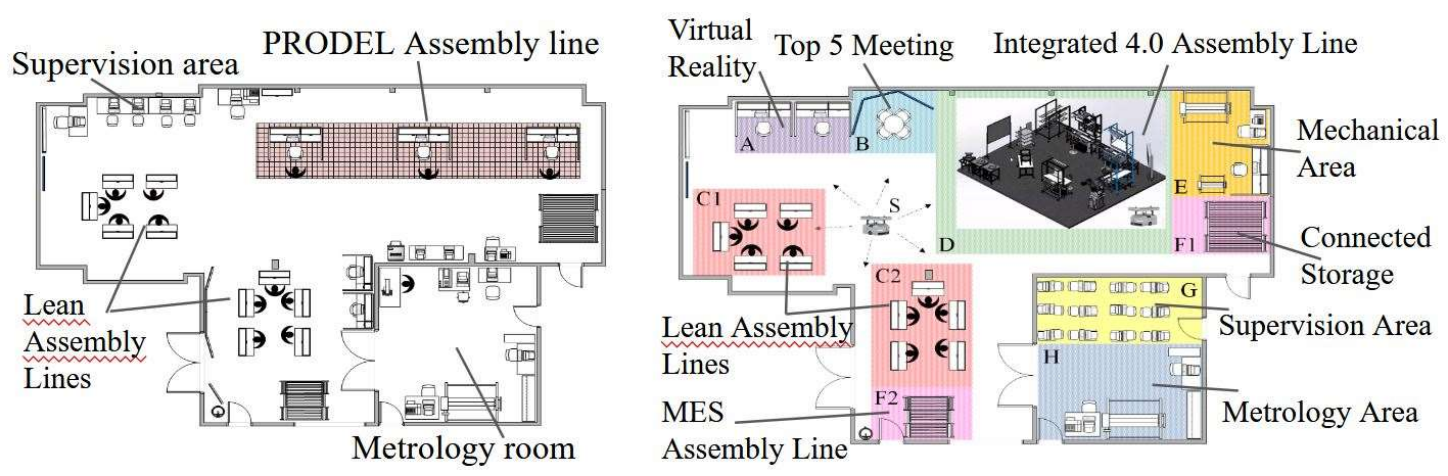

Fig. 2. Before and after layout of the learning factory.

Fig. 2 shows a previous layout of the LF (on the left). The LF is dedicated to the manufacturing industry. It included 2 manual assembly production lines, the cellular assembly PRODEL line and different logistics equipment such as Hanel dynamic store and line-side stores, and the metrology room with Mitutoyo machines. Fig. 2 presents, on its right side, the future "production hall 4.0". It has been developed thanks to the need analysis and it includes the future LF 4.0. These new areas are autonomous and allow satisfying many pedagogical needs. Works on ergonomics and mainly on the creation of a virtual ergonomics twin are studied in the virtual reality area "A". The area "E" consists of mechanical machines and allows to apprehend aspects of the life cycle of a product, from the design to the recycling of the product, but also skills on SMED and preventive maintenance. The manual 
assembly lines "C1" and "C2" bring for the first one the Lean approach, for the second one the basic 4.0 skills, such as the RFID data feedback and the homemade MES. Finally, the quality of the products is apprehended in the "H" metrology room, in particular thanks to connected metrology tools. Areas B, D, S and G of the future LF. Thanks to latest generation equipment such as a cobot, assisted workstations, connected warehouses, automated conveyors, and thanks to MES, ERP and supervision software solutions, the flow and information data of the future manual assembly line "D" will be completely integrated. Finally, the autonomous AMR robots interconnect the different areas of the LF. The interoperability of all of these software packages ensures the collection and continuity of data required for a LF 4.0. To answer every pedagogical need, pedagogical scenarios are created. They allow the development of technical skills on technologies in the context of specific industrial issues. The pedagogical scenarios should be flexible and able to support the learning paths from the basic production to the 4.0 .

\subsection{Example of "virtual reality” zone design}

As an illustration of the application of our approach, we propose the zoom of the interrelational crossboard shown on Table 1. Four technological needs are crossed with industrial needs which leads us to the pedagogical needs. Dedicated equipment such as headset, glasses, screens are implemented on the workstations to support human operators in their work. On the other hand, the acquisition of robot, cobot or event exoskeleton permits to automatize the work and help human operators in the hard tasks. Sensors and RFID technology participate in traceability and quality guarantee. The creation of a digital twin, thanks to production line and human operators digitization, allows to simulate the production process and to make the ergonomics study of human operators. The cybersecurity necessitates the digital shadow. To meet each of the pedagogical needs, pedagogical scenarios are created. They allow the development of technical skills on technologies in the context of specific industrial issues.

Table 1. Area, Equipements and Software of the University of Strasbourg.

\begin{tabular}{lcc}
\hline \multicolumn{1}{c}{ Industrial needs } & $\begin{array}{c}\text { Production/Logistics/Maintenance } \\
\text { Production execution }\end{array}$ & $\begin{array}{c}\text { Product/Product design } \\
\text { Process design (engineering) }\end{array}$ \\
\hline $\begin{array}{l}\text { Advanced robotics (robots, cobots, } \\
\text { exoskeleton, sensors, RFID) }\end{array}$ & Collaboration with humans, Automatized work, Traceability \\
Virtual and augmented reality & $\begin{array}{l}\text { Virtual human operator, support } \\
\text { equipment (headset, glasses,...) }\end{array}$ & Digital Twin, Dedicated equipment \\
Simulation (Witness, Plant, EMA) & Results of production simulation & Ergonomy study \\
Cybersecurity & & Digital shadow \\
\hline
\end{tabular}

\subsection{Educational component}

The pedagogy organized around the LF is based on three classic pillars: the objectives, the method and the evaluation [10]. The consistency between these three pillars is sought. This is to ensure that the evaluations relate to the objectives announced and developed over the course of the program. This same principle of alignment is also found in programs designed to support the development of specific skills. The learning and evaluation methods go through the development of successive tasks in a "Learning and Evaluation Situation". These situations are opportunities to develop and apply the skills sought. They are representative of real situations linked to the future professional context of the students. Students thus develop skills through action. In a realistic context, the complexity of the problems then takes on its full meaning for the students. On the basis of resources previously mastered and newly acquired during the project, they must then construct an original response. The assessment of skills is based on the student's ability to act in these situations. It will take different forms, often including direct observation and a report supplemented by an oral defense. The students will integrate their teachers' feedback into this report.
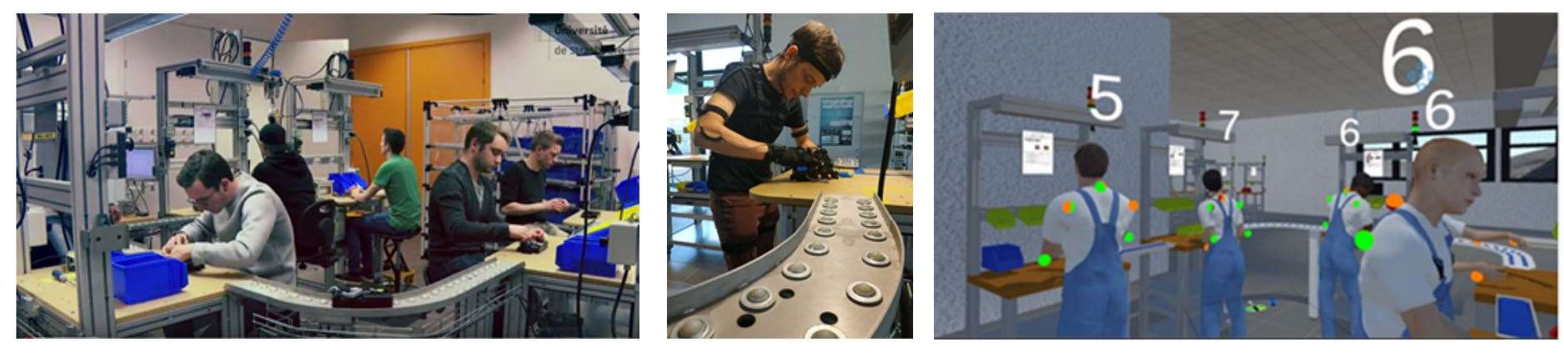

Fig. 3. The physical system, the activity of modeling and the resulting digital twin. 
Different pedagogical scenarios are therefore required to deal with the identified configurations of technological and industrial issues. For example, the digital numerization of a manual production line should be possible and integrated in the specification of a LF 4.0. As a resulting illustration of our LF, fig. 3 considers the development of the skill "modeling of industrial processes to simulate and optimize their operation". Fig. 3 presents the different steps of data acquisition to digitize a working environment (practice with a suit of sensors) and the final digital twin obtained through this pedagogical activity.

Based on this example, the professional situation is "Ergonomy study of human work". The targeted competence is to "Manage the human work tasks" and students have to simulate different work situations, to compare them and optimize the workstation configuration.

\section{Conclusion}

In the current competitive industrial context, companies tend to profit of the potential of performance provided by the Industry 4.0 tools. With an up-to-date skilled workforce, companies will thus be able to gain in agility, efficiency and profitability. They will also be able to fit more easily into 4.0 logistics chains (from suppliers to the end customer). Skills become a driver of technology acceptance and a key for the employees' development. To integrate dedicated teachings focused on Industry 4.0, universities have therefore to revise their pedagogical programs and means. This article aims to propose an interaction model of the needs to be covered with an LF 4.0 project and a canvas to achieve the specifications. We applied this proposal on our existing LF previously focused on Lean. Our LF is dedicated for the training of future employees in the 4.0 context and future actors of the 4.0 transformation in the manufacturing industry.

Regarding the perspective of this proposal, in the case of a company having a human resource service able to deal with the skill problem, a diagnostic could help to determine the specific missing skills in their workforce. Then a selection of the workers for training could be done without real difficulties. In the case of small companies, a support can be necessary to develop the training plan of the employees. These two points represent a perspective of development for us. A human resource management support to assist in defining the required skills and the associated learning paths on the LF therefore has to be developed.

\section{Acknowledgement}

This research is carried out within the framework of the Offensive Sciences project number 13.11 "Virtual Innovative Real Time Factory " (VIRTFac) which benefits from the financial support of the Offensive Sciences programme of the Upper Rhine Trinational Metropolitan Region, the INTERREG V Upper Rhine programme and the European Regional Development Fund (ERDF) of the European Union.

\section{References}

[1] A. Aljinovic, M. Crnjac, G. Nikola, M. Mladineo, A. Basic, V. Ivica, Integration of the human-robot system in the learning factory assembly process, Procedia Manuf., 45 (2020) 58-163.

[2] C. Prinz, F. Morlock, S. Freith, N. Kreggenfeld, D. Kreimeier, B. Kuhlenkötter, Learning Factory Modules for Smart Factories in Industrie 4.0, Procedia CIRP, 54 (2016) 113-118.

[3] H. Bauer, F. Brandl, C. Lock, G. Reinhart, Integration of Industrie 4.0 in Lean Manufacturing Learning Factories ", Procedia Manufacturing, 23 (2018) 147-152.

[4] P. R. Devika, A. Venugopal, B. Thiede, C. Herrmann, K. S. Sangwan, Development of the Transversal Competencies in Learning Factories, Procedia Manufaturing, 45 (2020) 349-354.

[5] L. F. Leal, A. Fleury, E. Zancul, Starting up a Learning Factory focused on Industry 4.0, Procedia Manufacturing, 45 (2020) 436-441.

[6] H. Oberc, M. Reuter, M. Wannöffel, B. Kuhlenkötter, Development of a learning factory concept to train participants regarding digital and human centered decision support, Procedia Manufacturing, 23 (2018) 165-170.

[7] E. Abele, G. Chryssolouris, W. Sihn, J. Metternich, H. ElMaraghy, G. Seliger, G. Sivard, W. ElMaraghy, V. Hummel, M. Tisch, S. Seifermann, Learning factories for future oriented research and education in manufacturing, CIRP Annals, 66 (2017) 803-826.

[8] I. Deniaud, F. Marmier, J. L. Michalak, Méthodologie et outil de diagnostic 4.0 : définir sa stratégie de transition 4.0 pour le management de la chaîne logistique, Logistique \& Management, (2019) 1-14.

[9] D. Plorin, Gestaltung und Evaluation eines Referenzmodells zur Realisier ung von Lernfabriken im Objektbereich der Fabrikplanung und des Fabrikbe triebes Dissertation, Chemnitz. Techn. Univ. Inst. für Betriebswiss und Fabriksysteme, Chemnitz, (2016).

[10] J. Biggs, Aligning teaching and assessing to course objectives, Int. Conf. Teach. Learn. High. Educ. New Trend Innovation, 2 (2003) 